\title{
Late Quaternary variations in monsoon induced upwelling and oxygen minimum zone in the eastern Arabian Sea: A study based on the thecosome Pteropod assemblage and Total Organic Carbon of sediment
}

\author{
JeEt MAJUMdeR $^{1, *}$, ANIL K GUPTA ${ }^{1}$, PANKAJ KUMAR ${ }^{2}$, \\ MOHAN KUPPUSAMY ${ }^{3}$, NIRMAL B ${ }^{3}$ \\ ${ }^{1}$ Dept. of Geology and Geophysics, Indian Institute of \\ Technology Kharagpur, India (*correspondence: \\ jeetgeology@gmail.com) \\ ${ }^{2}$ Inter-University Accelerator Center, New Delhi, India \\ ${ }^{3}$ School of Civil Engineering, Vellore Institute of \\ Technology (Chennai Campus), Chennai, India
}

Sediment core samples from the outer continental shelf, in the eastern Arabian Sea (EAS), have provided an opportunity to get an insight into the temporal variability in pteropod assemblages driven by monsoon variability and associated oceanographic processes. The studied core (SK291/GC-17) was collected at a depth of 182 meters below the sea surface. It is just below the upper horizon of the presentday Oxygen Minimum Zone (OMZ) and well above the Aragonite Compensation Depth (ACD). Pteropod assemblages associated with variation in Total Organic Carbon (TOC) suggest higher primary production due to coastal upwelling during $\sim 11000-9000$ and $\sim 5000-3600 \mathrm{Cal}$ yr BP. Heliconoides inflatus (previously known as Limacina inflata), dominates the pteropod population, whereas Limacina trochiformis which is a good upwelling indicator, is the second most dominant taxa. A sharp peak of pteropod abundance around $\sim 12000 \mathrm{Cal}$ yr BP coincides with the beginning of the Holocene climatic conditions. Following this, there was a gradual increase in productivity and TOC content of sediment until a sudden drop between $\sim 9000-8000$ $\mathrm{Cal} \mathrm{yr}$ BP. The pteropod shells in the outer continental shelf were corroded by the upper OMZ water but were not dissolved because the water was sufficiently saturated with aragonite. The late Holocene interval is also marked by a significant increase in the number of epipelagic pteropods caused by higher surface productivity and decreasing abundance of mesopelagic pteropods caused by the shoaling and intensification of the OMZ that inhibits the diel vertical migration of mesopelagic pteropods. 